\title{
Rethinking Special Collections Moves as Opportunities, not Obstacles
}

In the summer of 2017, the Marian Library—a special library devoted to the Blessed Virgin Mary within the larger University of Dayton Libraries systemcompleted a move of its rare book and archival collections into a new space within the main library building. The space, previously leased to the Society of Mary provincial archives, was already outfitted with a Liebert system for temperature and humidity controls, as well as shelving and some furniture.

Prior to the move, the rare book collection and archival holdings were stored in less than ideal conditions. In 2014, a consultant from Lyrasis conducted a preservation assessment that confirmed much of what we already knew: the space had wildly fluctuating temperature and humidity levels, which were causing damage to the collections. Most of the shelves were filled to capacity, an issue that challenged our ability to expand our holdings. Finally, the physical layout of the stacks room, with multiple entry points from the public areas of the library, made it difficult to secure the materials effectively.

The Marian Library has approximately 12,000 rare books and 1,300 linear feet of manuscript collections. The rare book collection includes medieval manuscripts and incunabula, as well as theological and devotional material from around the world; one area of strength, for example, is early Mexican imprints on the topic of the Virgin Mary. The archival collections include personal papers; institutional records; collections of postcards, holy cards, and photographs; and realia such as rosaries, scapulars, and medals. The relatively small size of the collection made it possible to undertake the move with library personnel, something that would not be an option for a larger collection (for comparison, consider recent collection moves at the Bancroft Library and the Beinecke Library). ${ }^{1}$

1. For further insight into the Beinecke Library collection move, see Rebecca Hatcher and Natalia Sciarini, "To Close, or Not to Close: That Is the Question" (presentation, IFLA World Library and Information Congress, Wrocław, Poland, August 19-25, 2017), available at http://library.ifla.org/1673/1/170hatcher-en.pdf [accessed 23 August 2017].

(c) 2017 by Colleen Hoelscher and Sarah Burke Cahalan (CC BY-NC [https://creativecommons.org/ licenses/by-nc/4.0/]). 
The planning process for the move took several months, starting in spring 2016. The move itself was delayed by some of the surprises of the process-it took significantly longer than anticipated for some work to be completed by the facilities department and their external contractors-but the time of the delay was filled with work on an inventory and preparatory work in the new space. The rare book move was completed in spring 2017, with the archives move completed in summer 2017. All of this work was completed in addition to the regular duties of library personnel; it was typically done in short shifts of several hours at a time.

The opportunity to move our most precarious materials into a better-controlled space was welcome. It also came at an advantageous time; in addition to the aforementioned preservation assessment, library staff had recently completed revisions to the library's disaster plan and collection development policy that helped frame decision-making throughout the move process. Having recently worked on these documents put library personnel in a frame of mind to consider collection care as part of the workflow for a collection move. Knowing just how overdue the collection was for improved conditions prompted prioritization of processes (such as an inventory and a basic conservation assessment) that elongated the timeline but also made the move more successful.

Moving special collections is a challenge under any circumstances, and our move was not without difficulty. However, we found that a large-scale collections move was more than just a series of obstacles to overcome; it was an opportunity for the library to improve physical space, stakeholder relationships, library practices, and the condition of the collections.

\section{Literature Review}

Surprisingly, very little has been written about moving special collections, particularly collections composed of both archival materials and rare books. Steven Carl Fortriede's 2010 monograph Moving Your Library, published by ALA, serves as a general reference work for library moves, with a focus on moving entire building contents. ${ }^{2}$ For those moving a general library collection, this would serve as a wonderful how-to manual, but it has almost no discussion of rare books or archives. Other works, such as Joanna M. Burkhardt's article "Do’s and Don'ts for Moving a Small Academic Library" and Jennifer S. Murray's "How to Survive a Library Move Instead of It Controlling You," present case studies from general library moves. ${ }^{3}$

2. Steven Carl Fortriede, Moving Your Library: Getting the Collection from Here to There (Chicago: American Library Association, 2010).

3. Joanna M. Burkhardt, "Do’s and Don'ts for Moving a Small Academic Library: Fourteen Helpful Tips," College \& Research Library News 59, no. 7 (1998): 499-503; Jennifer S. Murray, "How to Survive a Library Move: Control the Move Instead of It Controlling You," AALL Spectrum 10, no. 1 (2005): 18-19, 33. 
More has been written within the archival literature, although here, again, the literature tends to be based on case studies. Notable in this group is John Newman and Walter Jones's Moving Archives: The Experiences of Eleven Archivists, a collection of case studies from a variety of different kinds of repositories. ${ }^{4}$ Though written more than twenty-five years ago, Mary Frances Morrow's article "Moving an Archives" includes timeless advice concerning timetables and the inevitability of delays. ${ }^{5}$ The articles by Pam Hackbart-Dean et al. and Ted Ling discuss the practical details of moving archival collections, particularly when working with an outside moving company. ${ }^{6}$ More recently, a session at the 2017 IFLA World Library and Information Congress featured speakers from five different libraries, highlighting the value of incorporating preservation planning into a special collections move. ${ }^{7}$

One particularly helpful resource in our preparation was a March 2016 webinar presented by Frances Harrell on "Moving and Renovating: Collection Concerns." This webinar, sponsored by the Northeast Document Conservation Center, focused on the nitty-gritty aspects of handling and securing rare books and manuscripts when moving to a new location. Further resources included a network of colleagues who had executed special collection moves in the past. Consulting with peers who had experiences with moves similar in scale helped inform our supplies list and anticipated timeline.

Throughout the literature on library collection moves, there are recurring themes of challenges, unexpected obstacles, and time delays. However, a collections move also provides an opportunity to reflect and act on the collection as a whole. Some of the specific actions we incorporated into the Marian Library move may be scalable for larger or smaller collections, while others are applicable only to our unique situation; but whatever the needs of a particular library or archive, all collection moves are a chance to step back and think broadly about the collection. A collection move-whether relocating a few shelves of books or an entire library-is an opportunity to address issues beyond the physical location of library materials.

4. John Newman and Walter Jones, Moving Archives: The Experiences of Eleven Archivists (Landham, Md.: Scarecrow Press, 2002).

5. Mary Frances Morrow, "Moving an Archives," American Archivist 53, no. 3 (1990): 420-31.

6. Pam Hackbart-Dean, Leah Agne, and Julie Mosbo, "History on the Move: Relocating Special Collections and Archives," Provenance 28 (2010): 31-57; Ted Ling, "Shifting the Sands of Time: Moving an Archive," Journal of the Society of Archivists 21, no. 2 (2000): 169-81.

7. "Session 170: Libraries: A Call to Action/Best Practices in Moving Collections from the View of Preservation and Conservation" (presentation, IFLA World Library and Information Congress, Wrocław, Poland, August 22, 2017), available online at http:/ /library.ifla.org/view/ conferences/2017/2017-08-22/795.html [accessed 23 August 2017].

8. Frances Harrell, Moving and Renovating: Collection Concerns (webinar, March 22, 2016). This live webinar is periodically offered by the Northeast Document Conservation Center, most recently in March 2017. A full training schedule can be accessed at https:/ / www.nedcc.org/preservation-training/ training-currentlist [accessed 23 August 2017]. 


\section{Opportunity \#1: Improve the Physical Space}

One of the important mantras we returned to over the course of this project is "it's better than it was before." This sentiment captures both the improved conditions for the collections and our resignation to the reality that "better" is a far cry from "perfect." Unless a space is being built from scratch to your specifications, any collection move will include a series of attempts to fit round pegs into square holes. A new space planned around a collection would be designed with appropriate security settings, environmental controls that meet professional standards, and, most important, adequate space for the entire collection and future growth.

In our case, we were delighted to have additional space, some of which had environmental controls that are not present elsewhere in the building. However, the area with these controls was not large enough for all of our special collections materials. We had to choose among the materials, prioritizing materials for better conditions and enhanced security based on potential for theft and inherent vice of a given medium.

Prioritizing the safety and long-term security of the collection created additional work for library personnel. Some of the shelves that we inherited were constructed of wood, which over time will "off-gas" and can damage paper materials. ${ }^{9}$ We did not have the budget to replace these shelving units, so instead used the opportunity, still a tedious job, to cover the shelves with MarvelSeal, a "multilayered aluminized nylon and polyethylene barrier film [that] resists transmission of water vapor and off-gassing from wooden surfaces" frequently used in the framing and shipping of fine art. ${ }^{10}$ The film itself is relatively inexpensive; the real cost was in the time and labor it took to line dozens of wooden shelves. When viewed through the lens of collection safety and security, however, the decision to undertake the project was easily made.

Moving to a new space can also be an opportunity to address concerns about legacy practices and legacy equipment. Like most special collections libraries, we had some practices in place that were not in keeping with current professional standards. Moving to a new space gave us the opportunity to implement stricter access policies, while also improving security with the installation of a badge reader (the former space was secured only by a keyed lock). Framing these changes as a result of the move reduced pushback from staff and patrons alike.

9. Mary Lynn Ritzenthaler, Preserving Archives \& Manuscripts, 2nd ed. (Chicago: Society of American Archivists, 2010), 175-77.

10. Product description from Gaylord Archival website, available online at www.gaylord.com/Preservation/Conservation-Supplies/Wrapping,-Lining-\%26-Support-Materials/Marvelseal\%26\%23174\%3B360-Barrier-Film-(50-ft-)/p/M3650 [accessed 1 May 2017]. 
In addition to lax security, one of the most pressing issues facing our former space was overcrowding. As new archival materials and artwork were acquired since the library's founding in 1943, collections were squeezed in wherever there was room, often using suboptimal storage furniture salvaged from elsewhere on campus. The blank slate presented by a new space allowed us to design the room in a deliberate manner, with a focus on flexible growth and sustainable storage practices. Rare books were shelved with empty space left on each range to account for future accruals. New flat file cabinets were purchased, allowing us to ameliorate the storage conditions for a collection of engravings that were overcrowded in their former home. We even delayed the move so that "bonus" projects-including the installation of wireless network infrastructure, requiring asbestos abatement-were completed before materials began to move.

The move was an opportunity to improve other equipment beyond storage furniture. The library had a longstanding modus operandi of "making do," which resulted in rickety book carts, damaging bookends, and insufficient kick stools. Wrapping these purchases into the budget requests for the collection move allowed us to perform long-overdue upgrades. We self-imposed a rule that no subpar equipment would move with the collection materials to the new space, allowing it to be a truly "new" space. In some cases this lengthened our timeline; for example, it was necessary to wait until the end of the fiscal year to purchase some of the items desired for the space. However, thanks to the emphasis on the damage caused by problematic equipment in the 2014 preservation assessment, it was relatively easy to justify delaying parts of the move to accommodate the purchase of permanent upgrades in place of make-do solutions.

Working on a project like this put the library staff in a position to explain both to the library and university administration why the collection needs even better facilities. Every planning or budget meeting is a chance to advocate strategically for your collections. We sincerely hope that this particular storage solution is a five- to ten-year situation for the Marian Library and that the process of planning it and implementing a new space is a dry run for a move to a facility that can provide ideal environmental and security conditions for the whole collection, as opposed to just a majority of the rare books and archives. But even if the collections stay in this space for longer than that, we take comfort in knowing the conditions are better than they were before.

Moving special collections requires a tremendous output of time and effort, and reappointing this inherited space to suit our needs posed numerous hurdles. However, when viewed as an opportunity to improve physical conditions for our materials, the obstacles diminished in comparison. 


\section{Opportunity \#2: Communication with Stakeholders}

The stakeholders for this kind of project include collaborators from other departments on campus, colleagues in other areas of the library, patrons of the library, and the coworkers who are instrumental in implementing the move. The communication involved to keep all of these groups informed is time-consuming in and of itself, but we made use of meetings, widely distributed meeting minutes, our department's newsletter, and social media to get the word out about the collection move. It was important to incorporate discussion of the move into conversations with teaching faculty who frequently use the collections for their classes, as well as with researchers whose access to materials may be curtailed during the move.

Of course, the primary value of communication is to keep stakeholders informed. For instance, the Marian Library shares a building with the University of Dayton's Roesch Library (the main library on campus, serving undergraduates, graduate students, faculty, and staff), and library personnel from other areas needed to be informed of move activities that impacted them: namely, the freight elevator being commandeered for move-related purposes, and special collections staff needing to be excused from occasional committees, meetings, and other obligations during this time. This communication had other positive results; specifically, increased communication improved project buy-in from outside our department.

Communicating a move to patrons requires nuance and care. Our regular patrons were concerned about the possibility of items being unavailable during the move, and changes in reading room routines can make even the most stalwart academic tremble. We viewed the collection move as an opportunity to educate our patrons about best practices by explaining why our location and procedures were changing and being very open when answering their questions. Anecdotally, several researchers with extensive experience conducting archival research in other libraries, both in the United States and abroad, expressed relief that Marian Library special collections were going to be housed in an improved climate and with stricter security controls.

The meetings with facilities, public safety, IT, and external contractors that were necessary when retrofitting this space also served to improve communication with these stakeholders. The reality is that, even after the move is complete, we will continue to work with these groups: facilities is responsible for calibrating the temperature and humidity in our building, IT is responsible for making sure the security access system works, cleaning in the libraries is done by an external contractor, and so on. These meetings were opportunities to better explain —or, in some cases, to explain for the first time- - what sorts of practices are vital for the preservation and security of special collections materials. This improved communication worked 
both ways; we also found out through these meetings that parts of our inherited space were in violation of building codes and could be placing our staff and patrons at risk. Implementing the required changes added some time to the project and is in fact an ongoing process. Improving our relationships with facilities stakeholders will have a long-lasting, positive impact on the safety of our staff and collections.

We have an open house event planned in the new space for fall 2017, to which we will invite all of these stakeholders who have collaborated or supported the project over its unfolding-library staff, patrons, and vendors. We want them to understand how valuable their involvement has been, since it has made it possible for us to be better stewards of a world-class collection of special collections materials - materials that are central to the University of Dayton's identity as a Catholic institution.

\section{Opportunity \#3: Better Conditions for Collections}

When faced with a monumental task like a collection move, it may seem absurd to suggest looking for more projects to include. However, a collection move is a unique opportunity, and we assert that it is worth extending the timeline of the move if doing so creates useful data for future work. A large-scale move like this is the only time that every book and box in a collection will be physically handled within a short span of time. That level of individual attention creates opportunities for improved control and preservation of a collection.

In her NEDCC webinar on "Moving and Renovating," Frances Harrell emphasized the importance of checking each item off against a copy of your inventory when it leaves its original shelf and checking it in on another inventory when it is placed on its new shelf. This is well and good, but it does necessitate the production of a complete inventory.

To begin, a librarian in the Marian Library worked with our colleagues in the Information Systems and Digital Access unit (which maintains the Libraries' Sierra system) to extract a shelflist of the rare book collection. The list was transformed into a spreadsheet that was printed and checked against the collection by a library assistant and several student employees - the first full shelf reading of the rare book collection in recent institutional memory. From this process, the spreadsheet was updated with information about items that seemed to be missing. Fortunately, many of the "missing" items were found in the process of the move.

Critically, the shelf reading was conducted before the move began. This made the list as accurate as possible when it was used during the move itself. As each item came off the shelf, it was checked off on a paper copy of the list. As each item was 
shelved in its new location, it was checked off against another paper copy of the list. The personnel responsible for each action initialed and dated the lists. In the future, if an item goes missing, we can say with certainty that it was either missing before the collection move or that it has gone missing subsequent to the collection move. A similar process was completed at the box level for the archival collections.

The result was an accurate accounting of our collections at the time of this move, giving us greater intellectual control over our holdings. Keeping track of information about items that are missing or that have been located in the course of the move is time-consuming, as good data management is often time-consuming. But this is powerful data. Fortunately, in our case, not many collection items are actually missing, but being able to inform stakeholders that a certain number of items are in fact missing is a powerful argument when making the case for increased collection security.

Because of the relatively manageable size of the Marian Library's collections, we chose to undertake the move using library personnel, as opposed to external contractors who would have to be trained in best practices for material handling, identifying conservation needs, and so on. The personnel of the Marian Library recognized the need for this move, having observed the problematic conditions facing the collection firsthand. The project manager presented at department meetings about the specific workflows, which gave staff members opportunities to ask questions and provide feedback. She also prepared a "master document," which was an essential reference tool; this document laid out workflows, supply lists, and diagrams of the space, ensuring a consistent approach for a move with many individuals involved.

Basic preservation actions - like dusting books, removing paper flags left by researchers, adding support by tying linen ribbon around fragile books—also took place during the collection move. As part of the move, we also shelved all books over $40 \mathrm{~cm}$ horizontally, in accordance with best practice; previously, these oversized books had been shelved vertically, which can cause long-term damage to the books' spines. Relatively simple issues like these may have been overlooked when a book was not being handled, but the individual attention provided to each volume by the move created an opportunity to improve the conditions of the collection with extremely little effort.

Another step that we incorporated into the move workflow was flagging individual items that required further conservation needs. Like many religious collections, the Marian Library's rare books have been heavily used through the centuries. Many show the signs of use with dog-eared pages and marginalia, and in many cases 
these signs of use can be interesting and compelling. Many bindings are physically falling apart, and there has not been a budget for conservation work on these bindings. We thought that it would make sense to conduct a simple conservation assessment during the move, since it was a time when every book would be handled by library personnel. Initially, we considered a more elaborate flagging scheme, but we ultimately decided to simplify the process to recording "needs a box" and "needs professional work." The library administration hopes to incorporate these numbers, in particular the "needs professional work" numbers, into future grant applications and discussions with private donors.

The basic workflow of the move involved two members of library personnel at any given time. For the rare book move, a librarian worked alongside a paraprofessional library assistant. For the archives move, the same library assistant worked alongside an archivist, with contributions from a student employee. One person would remove items from the shelves and bring a book cart to the new location; the other would shelve the items in the new location. The inventory lists described above were checked off, initialed, and dated by each individual handling the materials to ensure accountability for every item's location.

In terms of staffing, it was articulated at multiple department meetings that the move would be a priority and that those who were not actively working on the move might need to pick up additional reference or other public service work. We made use of some additional student employee hours, and the move helped justify the retention of a temporary paraprofessional employee for a period beyond her initial contract. The Marian Library is a small unit, with five or six full-time employees (depending on how one counts), but we spread the work out in shifts over a period of months so that it was possible to incorporate the workflow into regular duties. The added benefit of having special collections personnel executing the move was that they did not need to be trained in materials handling or identifying conservation needs as part of the workflow.

Some of the work we incorporated into this collection move may not be scalable for a larger collection or a tighter deadline. But we encourage librarians to consider what might be possible while every item in a collection is being handled in a systematic way. Even if it is just an overdue dusting of collection items, some of the steps that slow the project down can also make it more successful.

\section{Conclusions}

Collection moves entail a significant amount of work, particularly when you take into account both the careful handling necessary for special collections and the surprises that arise when you bring external stakeholders into the conversation. Not 
surprisingly, the Marian Library collection move has taken considerably longer than we thought it would, but it has led to better conditions for the Marian Library's special collections and it has been an opportunity to learn more about the ongoing needs of the collections. In short, it is not perfect. Perfect, after all, is a moving horizon—but it is better than it was before.

A collection move can justifiably be seen as a series of formidable obstacles. It requires a tremendous amount of coordination, planning, teamwork, money, and time. Viewing the project as an opportunity, rather than just a series of logistical challenges, allowed us to improve the physical conditions of our space, update library practices, develop our relationships with stakeholders, and better serve our materials. Essentially, we did not rush the process. We incorporated into the move improvements to the space, to the equipment, and to our intellectual control over the collection. The benefits of these decisions continue to be manifest as both the staff and collection settle into a new space.

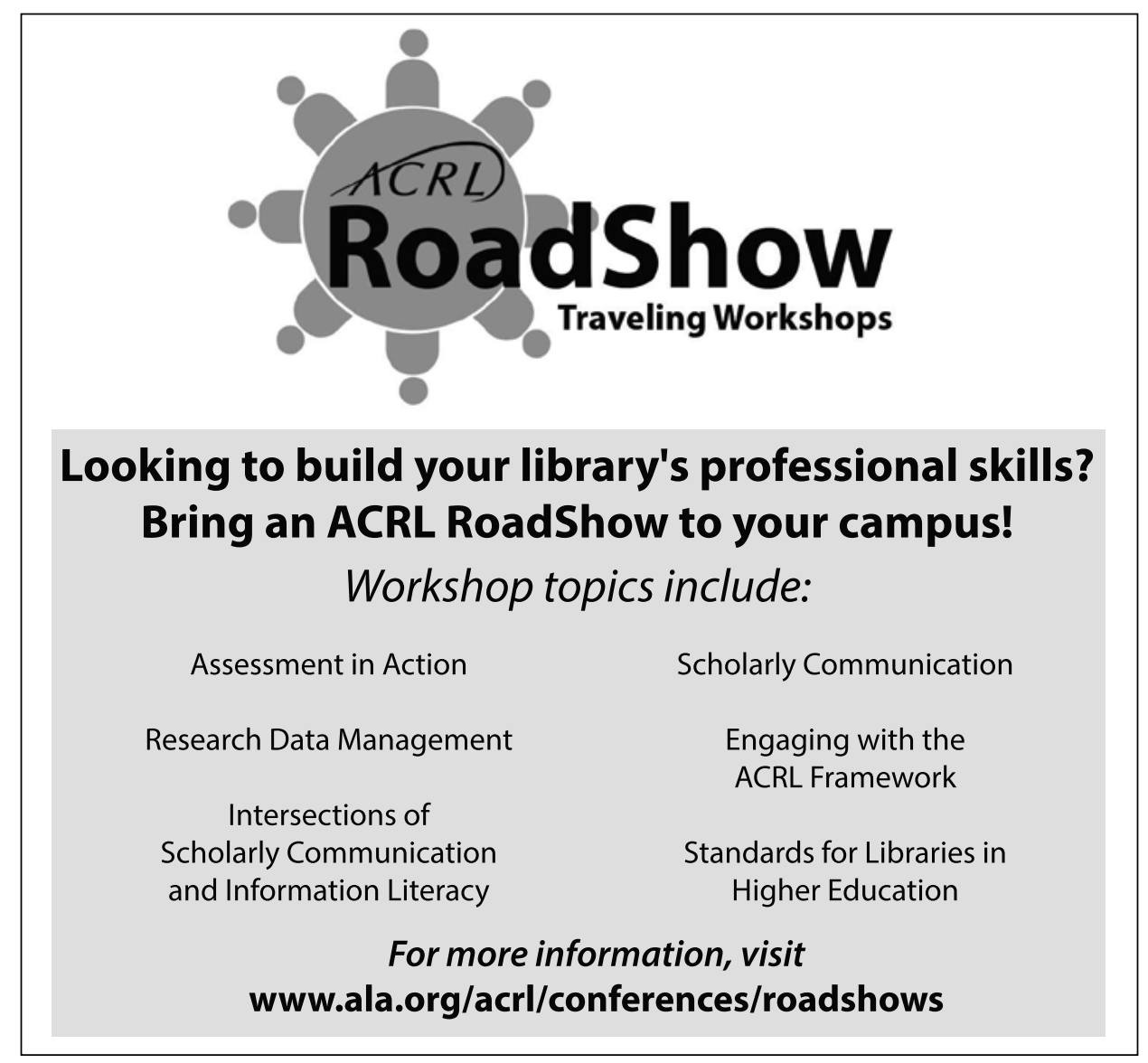

